\title{
New records of four reef fish species for Hong Kong
}

Allen W. L. To ${ }^{1 *}$ and Stanley K. H. Shea ${ }^{2}$

\begin{abstract}
Background: A total of four reef fish species: Amblyeleotris japonica, Halichoeres hartzfeldii, Canthigaster papua and a Parapriacanthus species, are reported for the first time in Hong Kong.

Methods: The specimens were discovered during underwater reef fish surveys. About 20 individuals of one Parapricanthus species were found at Tai Chau. A single Amblyeleotris japonica and a single Halichoeres hartzfeldii were both observed at the west coast of north Ninepin Island. One individual of Canthigaster papua was found at Clearwater Bay.

Results: The likelihood of these four species having been artificially introduced into Hong Kong waters is discussed and eliminated. Comparison of these four species is made against six other species previously encountered in Hong Kong waters that were not already documented in local records and suspected to be artificially introduced.

Conclusions: Four reef fish species, including Amblyeleotris japonica, Halichoeres hartzfeldii, Canthigaster papua and a Parapriacanthus species, are reported for the first time in Hong Kong. Details on the sighting records, locations, habitats and behavior of the observed individuals are described. The validity of the natural origin of these fish is discussed.
\end{abstract}

Keywords: Hong Kong, Reef fish, Native species, South China Sea, Amblyeleotris japonica, Halichoeres hartzfeldii, Canthigaster papua, Parapriacanthus

\section{Background}

Hong Kong Special Administrative Region of the People's Republic of China, located in the northern sector of the South China Sea, has about $1650 \mathrm{~km}^{2}$ of territorial waters and more than 200 offshore islands (hk-fish.net 2016a). The area of Hong Kong's territorial water is only about $0.05 \%$ of the South China Sea's, but marine fish diversity is about $30 \%$ of the latter (hk-fish.net 2016a). The sea in Hong Kong is host to a range of important fish habitats, including rocky reefs, coral communities and adjacent rubble and sandy areas (Morton and Morton 1983; Sadovy and Cornish 2000). Situated at the mouth of the Pearl River, the western coast of Hong Kong regularly receives large volumes of freshwater, increasing the turbidity and decreasing the salinity of marine water in the area. The effect of the Pearl River is progressively reduced towards the eastern waters of Hong Kong, leaving the south-eastern,

\footnotetext{
* Correspondence: allenwlto@yahoo.com

${ }^{1}$ WWF-Hong Kong, 15/F, Manhattan Centre, 8 Kwai Cheong Road, Kwai

Chung, New Territories, Hong Kong

Full list of author information is available at the end of the article
}

eastern and north-eastern coast of Hong Kong almost unaffected by the freshwater of the Pearl River (Morton and Morton 1983; Sadovy and Cornish 2000). Being more oceanic in nature, these eastern waters are home to the majority of more than 80 scleractinian coral species locally recorded (Chan et al. 2005).

Field studies on the reef fish diversity in Hong Kong so far have produced records of around 340 reef fish species (Sadovy and Cornish 2000; To et al. 2013). Four new records of reef fish species for Hong Kong sighted during underwater reef fish surveys from Jun 2014 to Nov 2015 is reported here, including a Parapriacanthus species, Amblyeleotris japonica Takagi, 1957, Halichoeres hartzfeldii (Bleeker, 1852), and Canthigaster papua (Bleeker, 1848).

Three species under the genus Parapriacanthus are currently recognized (Mooi 2001), of which Parapriacanthus dispar (Herre, 1935) and Parapriacanthus ransonneti Steindachner, 1870 are similar-looking species. At least part of their known native range is overlapping (Allen and Erdmann 2012). Parapriacanthus dispar has been recorded 
in Australia, Indonesia, the Philippines, New Caledonia, Papua New Guinea and the Solomon Islands (Allen and Erdmann 2012; Froese and Pauly 2016a). It has not been recorded in mainland China or Taiwan (Liu 2008; Wu 2012). The natural distribution of Parapriacanthus ransonneti is much more widespread in the Indo-west Pacific: from Red Sea to South Africa, eastward to the Marshall Islands, northward to southern Japan, and southward to Australia (Froese and Pauly 2016b). It is also found in mainland China and Taiwan (Liu 2008; Wu 2012). Nonetheless, species of the genus of Parapriacanthus have not previously been recorded in Hong Kong (Sadovy and Cornish 2000; To et al. 2013; hk-fish.net 2016b). Both species occur in aggregations and are found in caves and under ledges (Allen and Erdmann 2012). The two species can be distinguished by a combination of the number of lateral-line scales, dorsal fin spines, dorsal fin rays, and scales between the midventral edge of coracoid and the midlateral edge of the pelvic bone (Mooi 2001).

Amblyeleotris japonica occurs in the Indo-west Pacific Ocean, and is reported to occur natively in Israel, Japan, New Caledonia, Papua New Guinea, Saudi Arabia, Solomon Islands and Taiwan (Froese and Pauly 2016c), as well as in mainland China (Liu 2008), and the South China Sea (Shao 2016a). The species can grow to about $8.5 \mathrm{~cm}$ in total length (Froese and Pauly 2016c). It utilizes more coastal sheltered waters in sandy bottoms with scattered shell fragments and coral rubbles, and was reported to associate with alpheid shrimps (Yanagisawa 1976; Shoichi 2014; Shao 2016a). Its appearance resembles Amblyeleotris gymnocephala (Bleeker, 1853), with a considerably overlapping native range (Allen et al. 2015). Amblyeleotris japonica can be distinguished from Amblyeleotris gymnocephala by the presence of a C-shaped dark blotch on the caudal fin (Froese and Pauly 2016c), and the first dorsal fin being relatively more triangular in shape (Hayashi and Shiratori 2013). Of these two species, only Amblyeleotris gymnocephala has previously been recorded in Hong Kong (Sadovy and Cornish 2000; hk-fish.net 2016b).

Halichoeres hartzfeldii is found from the East Indian region to Micronesia and Samoa, southward to Australia and northward to Japan (Allen and Erdmann 2012; Shoichi 2014; Allen 2014; Allen et al. 2015). It is also found in mainland China, the South China Sea and Taiwan (Liu 2008; Wu 2012; Shao 2016b). It has not been recorded in Hong Kong (Sadovy and Cornish 2000; To et al. 2013; hk-fish.net 2016b). Halichoeres hartzfeldii can grow to $18 \mathrm{~cm}$ in total length (Froese and Pauly 2016d). This species can form small groups and occurs in sand and rubble bottoms near reefs (Allen and Erdmann 2012; Allen et al. 2015; Froese and Pauly 2016d). Halichoeres zeylonicus (Bennett, 1833) is very similar in appearance to Halichoeres hartzfeldii (Allen and Erdmann 2012;
Allen et al. 2015). There are records of Halichoeres zeylonicus in mainland China and Taiwan (Liu 2008; Wu 2012; Shao 2016c). However Halichoeres zeylonicus was also reported to be closely related to Halichoeres hartzfeldii, with its distribution restricted to the Indian Ocean and western Indonesia (Randall et al. 1997; Allen and Erdmann 2012; Allen et al. 2015). The two species can be distinguished by the less vivid banding on the head and the presence of a small oblique dark spot, or orange banding on the back, behind the level of the pectoral fin tip in male Halichoeres zeylonicus, and the noticeably thinner midlateral orange or yellow stripe in female Halichoeres zeylonicus (Allen and Erdmann 2012).

As detailed in the review by Matsuura (2015) on the taxonomy and systematics of tetraodontiform fishes, Canthigaster papua was previously regarded by Allen \& Randall (1977) as a synonym of Canthigaster solandri (Richardson, 1845). However they have recently been separated and recognized as two distinctive species (Allen and Erdmann 2012; Allen 2014; Allen et al. 2015). Canthigaster papua is described to have prominent orange colour around the mouth, and Canthigaster solandri has yellow-orange colouration on the tail (Allen and Erdmann 2012; Allen et al. 2015). The native range of Canthigaster papua is reportedly Indonesia, Philippines, Micronesia, Papua New Guinea, and from the Solomon Islands to the Great Barrier Reef and New Caledonia (Allen and Erdmann 2012; Allen et al. 2015). Canthigaster solandri is found in southwest Japan, Micronesia, and from east Australia to French Polynesia (Allen et al. 2015). Of the two species, only Canthigaster solandri are recorded to occur in mainland China and Taiwan (Liu 2008; Wu 2012), however it is unknown if these earlier records included Canthigaster papua, which was once considered as its synonym. Neither species have been recorded in Hong Kong (Sadovy and Cornish 2000; To et al. 2013; hk-fish.net 2016b). Canthigaster papua can grow to $9 \mathrm{~cm}$ in total length, and inhabits coral areas either solitarily or in pairs (Allen and Erdmann 2012; Allen et al. 2015).

\section{Methods}

A group of about 20 individuals of Parapricanthus species was noticed on 1 July 2015 by the first author (Fig. 1), at about $4 \mathrm{~m}$ depth off the coast of Tai Chau $\left(22^{\circ} 24^{\prime} 13.2^{\prime \prime} \mathrm{N} ; 1^{\circ} 23^{\prime} 05.93^{\prime \prime} \mathrm{E}\right)$, sometimes also known as Tsim Chau. Individuals were about $7 \mathrm{~cm}$ in total length. The group was observed for $10 \mathrm{~min}$, and was seen to swim quite rapidly back and forth between two large boulders 3-4 $\mathrm{m}$ apart, staying close to the boulders most of the time. Photographs were taken.

On 18 July 2015, one individual of Amblyeleotris japonica was observed resting within a burrow built on rubble habitat (Fig. 2), at the western coast of north Ninepin Island $\left(22^{\circ} 15^{\prime} 49.77^{\prime \prime} \mathrm{N} ; 114^{\circ} 20^{\prime} 43.45^{\prime \prime} \mathrm{E}\right)$, at about 


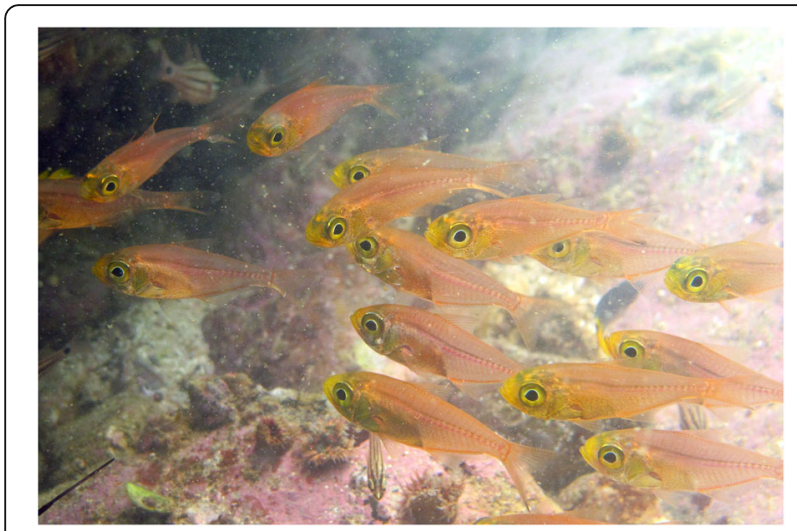

Fig. 1 A group of Parapriacanthus species observed at Tai Chau

$5 \mathrm{~m}$ in depth. The individual, which was estimated to be around $8 \mathrm{~cm}$ in total length, was observed for about 10 min during which half of the body remained outside the burrow. The fish looked very similar at first glance to Amblyeleotris gymnocephala which has been known to occur in Hong Kong waters. However, moving further out of the burrow, the fish displayed a prominent and distinctly triangularly shaped dorsal fin. A commensal shrimp was also noted to share the burrow with this individual.

One individual of Halichoeres hartzfeldii was observed on the same day (Fig. 3), 18 July 2015, at the same site: the western coast of north Ninepin Island $\left(22^{\circ} 15^{\prime} 49.77^{\prime \prime} \mathrm{N}\right.$; $\left.114^{\circ} 20^{\prime} 43.45^{\prime \prime} \mathrm{E}\right)$. The individual was observed at about $10 \mathrm{~m}$ in depth in rubble habitat, and swam around the authors for about 5 min during which observation was made and photographs were taken. The individual kept a distance of about 2-3 $\mathrm{m}$ away from authors and swam with a speed and form of the Halichoeres nigrescens (Bloch \& Schneider, 1801), which is known to occur in Hong Kong. The individual was about $10 \mathrm{~cm}$ in total length. Its

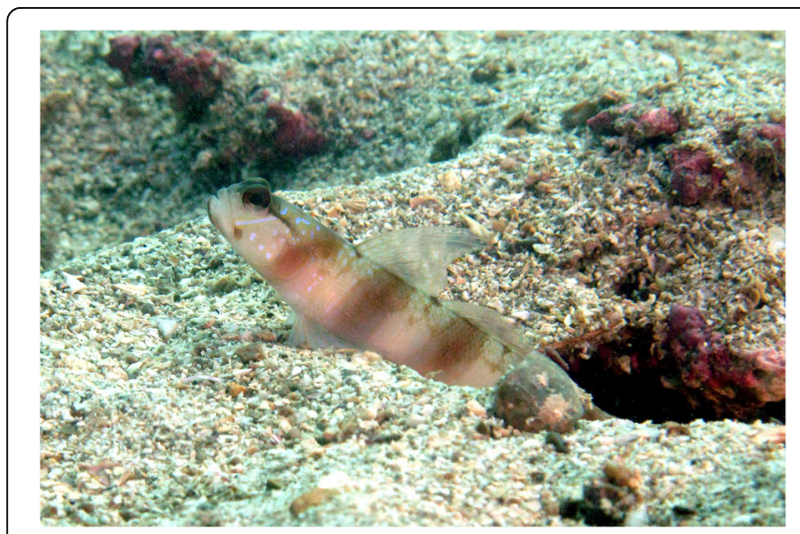

Fig. 2 Amblyeleotris japonica Takagi, 1957 observed at north Ninepin Island, staying at the entrance to its burrow

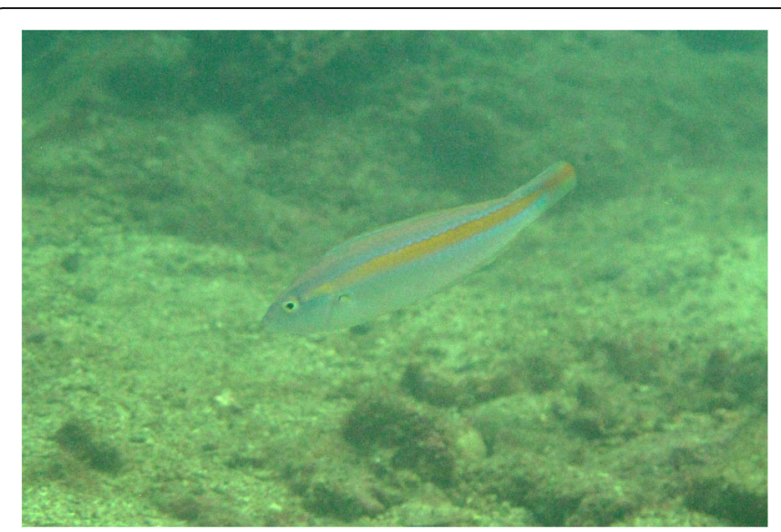

Fig. 3 Halichoeres hartzfeldii (Bleeker, 1852) observed at north Ninepin Island

body was pinkish near the dorsal with a prominent midlateral yellow stripe running behind the eye and throughout the body. The mid-lateral stripe on this individual was much thicker than that of the similar-looking Halichoeres zeylonicus, which is restricted to the Indian Ocean and western Indonesia (Randall et al. 1997; Allen and Erdmann 2012; Allen et al. 2015).

On 8 Nov 2015, one small individual of Canthigaster papua was observed at about $4 \mathrm{~m}$ deep over rocky reefs at Clearwater Bay $\left(22^{\circ} 16^{\prime} 18.06^{\prime \prime} \mathrm{N} ; 114^{\circ} 18^{\prime} 10.22^{\prime \prime E}\right)$ (Fig. 4). The bay is an artificially constructed sea wall, protecting a pier and a mooring area for privately owned yachts. The observed individual was about $4 \mathrm{~cm}$ in total length and was seen swimming over boulders covered with Diadema urchins. The individual was wary of the first author and swam among the spines of the urchin during the 10-min of the observation. Photographs were taken. The small individual had prominent orange colour around the mouth, which is a distinctive feature of Canthigaster papua, and lacked the yellow-orange colouration on the

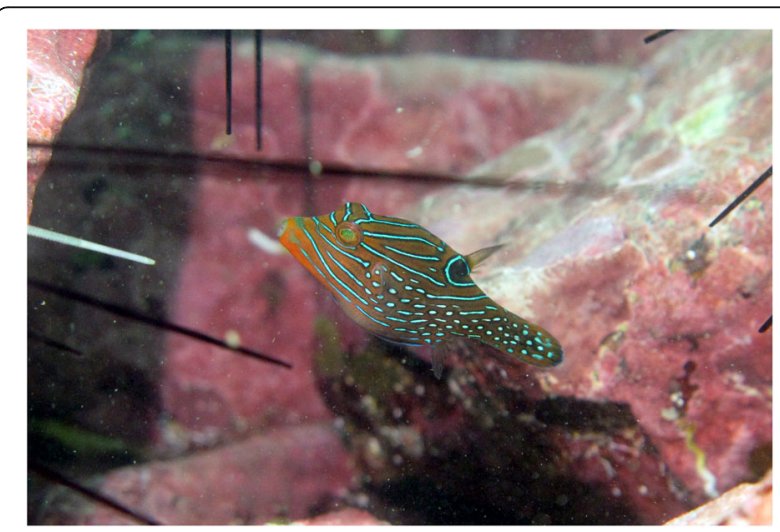

Fig. 4 Canthigaster papua (Bleeker, 1848) observed swimming among Diadema urchins at Clearwater Bay 
tail which is the feature for Canthigaster solandri (Allen and Erdmann 2012; Allen et al. 2015).

\section{Results and discussion}

New records of reef fish for Hong Kong have been published in many previous studies about Hong Kong reef fish faunal diversity (Sadovy and Cornish 2000; To et al. 2013), despite the more than 160 years of ichthyological research in Hong Kong (hk-fish.net 2016a). Notably, some sightings of reef fish, which would otherwise be new records to Hong Kong, were very likely artificially introduced, as noted by To et al. (2013). The occurrence of these reef fish might have originated from release by aquarium hobbyists who no longer wish to keep the fish for various reasons (To and Situ 2005). Fish records falling into this category usually have a few observable characteristics.

Firstly, if Hong Kong does not fall into the species' documented natural range, then this may be an indication that the species was artificially introduced. An example is the sighting of Zebrasoma xanthurus (Blyth, 1852) in the same survey, which is a species from the Indian Ocean (To and Situ 2005).

Secondly, if juveniles of a species have not been recorded locally, but a fully-grown adult is sighted in a publicly accessible location or in a fish sanctuary such as marine parks, then there is a possibility that the individual was artificially introduced. Examples include a previous sighting of an adult Pomacanthus imperator (Bloch, 1787) in an easily-accessible marine park in Hong Kong (To and Situ 2005). The individual's previous human owners might have chosen the marine park for releasing the fish after having grown tired of keeping it, believing that the marine park would offer it protection (To and Situ 2005). Past reports of a large Naso lituratus (Forster, 1801) and a fully-grown Acanthurus japonicus (Schmidt, 1931) for instance, were both locally unprecedented sightings that were rejected as new species to Hong Kong, as they were found in one of Hong Kong's most easily accessible, popular dive sites with open-access to anyone, which pointed to the likelihood of introduction by aquarium fish release for those individuals (To et al. 2013).

Thirdly, if the species is popular and available in the aquarium trade in Hong Kong, then there is an increased probability for individual occurrences in the wild to be results of artificial introduction. Although there are no recent studies on the aquarium fish trade in Hong Kong, an earlier study revealed a large diversity of reef fish involved in the trade (Chan and Sadovy 2000). A species' availability in the local trade can serve as an additional circumstantial evidence to the possible origin of individuals sighted in the wild, including the abovementioned sighting records of surgeonfish and angelfish.
An earlier sighting of a large Aulostomus chinensis (Linnaeus, 1766) individual of brown colour-type was regarded as a valid new fish record for Hong Kong, as it was observed in a relatively remote dive site, and was not found in the local aquarium trade (To et al. 2013). These key characteristics, together with other observations such as the presence of injuries which can link to recent captivity, lack of wariness of approaching divers and the suitability of the habitat to the fish observed, can further shed light on the likely origin of the observed reef fish species and their validity as new records for Hong Kong.

Notably, in addition to release by aquarium hobbyists, reef fish are sometimes released in religious activities (To and Situ 2005; To et al. 2013). Based on the authors' observations, reef fishes involved in this type of fish release mainly include species of Lutjanidae and Serranidae, but any other species available in local fish markets may also be purchased for release. The release of the fish can take place in near-shore areas, such as from public piers or jetties, or further from the shore areas through release from onboard fish-carrying vessels. Individuals introduced into the sea by such fish release activities may also be differentiated from naturally occurring fish by the same characteristics as described in the earlier section. For instance, the sighting of an individual of Epinephelus fuscoguttatus (Forsskål, 1775), which was observed to have injuries around the jaw, and encountered in shallow coral areas, was almost certainly a result of such fish release. The plate-size of that individual and the popularity of this species in the live reef food fish trade, which is centered in Hong Kong (Lau and Li 2000; Craig et al. 2011), further substantiates the evidence pointing towards fish release as the origin of that observed individual (To et al. 2013).

With reference to the above accounts of released fish characteristics, it arises that the present study represents the first valid documentation of the four reef fish species featured in this paper, in Hong Kong. Although these species may be available in the local aquarium trade, the individuals described were encountered in outlying islands (e.g. Tsim Chau and Ninepin Islands), or in sites that are relatively inaccessible to the public (e.g. Clearwater Bay), reducing the probability of release by aquarium fish hobbyists. In addition, fish released by aquarium fish hobbyists are typically bigger in size, abandoned by their keepers when they grow out of their tanks. The specimens observed by the authors, however, were relatively small. Furthermore, all four species presented here have previously been recorded in mainland China, meaning these species naturally occur in adjacent areas of the northern South China Sea regions. Hong Kong therefore falls within the species' natural ranges. Last but not least, the behaviour of the fishes and their interaction with the respective habitats appeared natural, 
further supporting the validity of these species as new records for Hong Kong.

Regarding the origin of these new fish records, a previous study on Hong Kong reef fish assemblage compared the reef fish species in Hong Kong with those of adjacent areas, and suggested that some of the rarer or sporadically occurring tropical species occurring in Hong Kong may have been transported as larvae from south of Hong Kong by the Hainan current (Cornish 1999). The presence of rare species at their juvenile stages in Hong Kong was suggested to further support the legitimacy of this possible pathway (Cornish 1999). Such transport of juveniles of tropical species into subtropical regions has also been noted in other places, such as the occurrence of tropical and subtropical fishes in temperate southeastern Australia (Booth et al. 2007), and in New Zealand (Francis et al. 1999). Likewise, the Taiwan current from the East China Sea invades Hong Kong in winter (Morton and Morton 1983), which potentially brings subtropical or temperate fish larvae species into Hong Kong (Cornish 1999).

Many reef fishes are known to produce pelagic eggs, including species in the families Pempheridae and Labridae, to which Parapriacanthus species and Halichoeres hartzfeldii belong (Sadovy and Cornish 2000; Allen et al. 2015). Species in the families Gobiidae and Tetraodontidae, although are known to produce demersal eggs (Sadovy and Cornish 2000), once hatched the pelagic fish larvae may also become dispersed (Sadovy and Cornish 2000; Lecchini 2005). Depending on the species, the larval stage of reef fishes can last for weeks or months (Leis and McCormick 2002). Notably, all four species reported in this study have been recorded in places nearby, such as mainland China and Taiwan. The close proximity of Hong Kong to places where these species naturally occur could have facilitated the transport and settling of fish larvae of these species in Hong Kong. Therefore it is reasonable to suggest that the occurrence of these four species may have been due to the transport of pelagic fish larvae. However, whether these rare or sporadically occurring reef fish species can establish and become self-sustaining populations in local waters is yet to be investigated.

Existing studies indicate that new fish records can be associated with the addition of new artificial structures. For example, a study conducted in the Mediterranean coast of Israel laid support to the possibility that impoverished areas offered "unsaturated" environments for new fish species, and in that particular case it was filled by Red Sea immigrants, such as sweepers (Diamant et al. 1986). New structures may have been placed in a way that intercepts incoming larvae originally destined for natural reefs down current (Cenci et al. 2011), therefore new fish species could be found in these artificial structures rather than in natural reefs. Notably, although fish assemblage in certain areas can largely be an extract of a common pool of larval recruits, the fish species diversity at a certain site can be affected by microhabitat selection by different species (Kaufman and Ebersole 1984). New artificial structures may offer to these recruits a suitable habitat to settle that is unique in the area concerned (Carr and Hixon 1997). Artificial structures therefore have been suggested to potentially facilitate the settling of new fish species.

Among the four new species found in Hong Kong as reported in this study, the single individual of Canthigaster papua was found in artificial structure-a man-made sea-wall for sheltering yachts. Although this study did not investigate the uniqueness of the micro-habitat offered by this particular sea-wall, it is worth noting that, from a macro point of view, such artificial structures is not unique within waters of Hong Kong where underwater reef fish surveys are conducted. In addition, this artificial structure has been put in place for at least 15 years. Therefore it is doubtful if this structure should be considered as a new artificial structure. Whether this artificial sea wall offers an "unsaturated" environment for new species to inhabit is difficult to judge. With limited information and research into this area, the current study is unable to quantify the significance of this artificial structure to the new fish species record.

Hong Kong's reef fish diversity, including other marine species, remains, to date, relatively unexplored. The discovery of the four species presented in this paper demonstrates the need for Hong Kong's reef fish, as well as other understudied marine fauna in Hong Kong, to be surveyed and documented, to produce an updated inventory of local marine species.

Currently, it is the priority of governments worldwide to manage the spread of non-native species (Bax et al. 2003; Thresher and Kuris 2004), and from these attempts the challenge of defining what a "native" species is, is realized (Gilroy et al. 2016). Without a comprehensive and up to date inventory of local species, Hong Kong will soon come upon the same roadblock in its marine conservation efforts.

Any future work in Hong Kong's marine biodiversity conservation, whether in the elimination of invasive species or the protection of native species, will greatly benefit from a clear understanding of the marine fauna present in local waters. Research into the presence and distribution of species within Hong Kong territorial waters, and the identification of biodiversity hotspots to be prioritized for protection, is hence recommended.

\section{Conclusions}

This study provides the first sighting records of Amblyeleotris japonica, Halichoeres hartzfeldii, Canthigaster papua and a Parapriacanthus species in Hong Kong. 


\section{Acknowledgements}

The authors would like to thank Professor K.T. Shao (Biodiversity Research Center, Academia Sinica), Dr. Andy Cornish (WWF) and Dr. Mark Erdmann (Conservation International) for advice on species identification in this study. The authors would like to thank the two anonymous reviewers for valuable comments to improve the quality of the manuscript. The authors would like to express deep gratitude to Fion Cheung and Kathleen Ho as dive buddies in this study and for their helpful comments during the preparation of this manuscript. The financial and technical support from Ocean Park Conservation Foundation Hong Kong (OPCFHK) in piloting this underwater reef fish survey is greatly appreciated. The Swire Group Charitable Trust kindly supported the expense of this publication.

\section{Funding}

Ocean Park Conservation Foundation Hong Kong (OPCFHK) provided financial support in this fish survey. The Swire Group Charitable Trust supported the expense of this publication.

\section{Availability of data and materials}

The dataset supporting the conclusions of this article is included within the article.

\section{Authors' contributions}

AWLT and SKHS are both involved in the field survey for reef fish in this study, and jointly identified the species included in this study. AWLT prepared the draft of the manuscript and processed photos. SKHS provided comments to the manuscript and contributed to drafting the manuscript. All authors read and approved the final manuscript.

\section{Competing interests}

The authors declare that they have no competing interests.

\section{Consent for publication}

Not Applicable.

\section{Ethics approval and consent to participate}

Not Applicable.

\author{
Author details \\ ${ }^{1}$ WWF-Hong Kong, 15/F, Manhattan Centre, 8 Kwai Cheong Road, Kwai \\ Chung, New Territories, Hong Kong. ${ }^{2}$ BLOOM Association, c/o, ADMCF, 9 \\ Queen's Road Central, Hong Kong.
}

Received: 16 June 2016 Accepted: 2 September 2016

Published online: 01 October 2016

\section{References}

Allen GR. Field guide to marine fishes of tropical Australia and south-east Asia. 4th ed. Western Australia: Western Australia Museum; 2014.

Allen GR, Erdmann MV. Reef fishes of the East Indies volumes I-III. Perth: Tropical Reef Research; 2012.

Allen GR, Randall JE. Review of the sharpnose pufferfishes (subfamily Canthigasterinae) of the Indo-Pacific. Rec Aust Mus. 1977;30:475-517.

Allen G, Steene R, Humann P, Deloach N. Reef fish identification tropical Pacific. 2nd ed. Florida: New World Publications; 2015.

Bax N, Williamson A, Aguero M, Gonzalez E, Geeves W. Marine invasive alien species: a threat to global biodiversity. Mar Policy. 2003;27:313-23.

Booth DJ, Figueira WF, Gregson MA, Brown L, Beretta G. Occurrence of tropical fishes in temperate southeastern Australia: role of the east Australian current. Estuar Coast Shelf Sci. 2007;72:102-14.

Carr MH, Hixon MA. Artificial reefs: the importance of comparisons with natural reefs. Fisheries. 1997;22:28-33.

Cenci E, Pizzolon M, Chimento N, Mazzoldi C. The influence of a new artificial structure on fish assemblages of adjacent hard substrata. Estuar Coast Shelf Sci. 2011:91:133-49.

Chan TC, Sadovy Y. Profile of the marine aquarium fish trade in Hong Kong Aquarium Sci Conserv. 2000;2(4):197-213.

Chan ALK, Choi CLS, MCCorry D, Chan KK, Lee MW, Put Jr A. Field guide to hard corals of Hong Kong. Hong Kong: Friends of the Country Parks; Cosmos Books Ltd; 2005.
Cornish A. Fish assemblages associated with shallow, fringing coral communities in sub-tropical Hong Kong: species composition, spatial and temporal patterns. PhD Thesis. Hong Kong: The University of Hong Kong; 1999.

Craig MT, de Mitcheson YJ S, Heemstra PC. Groupers of the world a field and market guide. South Africa: NISA (Pty) Ltd; 2011.

Diamant A, Ben Tuvia A, Baranes A, Golani D. An analysis of rocky coastal Eastern Mediterranean fish assemblages and a comparison with an adjacent small artificial reef. J Exp Mar Bio Ecol. 1986;97:269-85.

Francis MP, Worthington CJ, Saul P, Clements KD. New and rare tropical and subtropical fishes from northern New Zealand. New Zeal J Mar Fresh. 1999;33:571-86.

Froese R, Pauly D. Fishbase. 2016a. http://www.fishbase.org/summary/ SpeciesSummary.php?|D=61107\&genusname=Parapriacanthus\& speciesname=dispar. Accessed date 12 Jan 2016.

Froese R, Pauly D. Fishbase. 2016b. http://www.fishbase.org/summary/ Parapriacanthus-ransonneti.html. Accessed date 12 Jan 2016.

Froese R, Pauly D. Fishbase. 2016c. http://www.fishbase.org/summary/ Amblyeleotris-japonica.html. Accessed 8 Jan 2016.

Froese R, Pauly D. Fishbase. 2016c. http://www.fishbase.org/summary/ Halichoeres-hartzfeldii.html. Accessed 17 Jan 2016.

Gilroy J, Avery J, Lockwood, J. Seeking international agreement on what it means to be 'native'. Conserv Lett. 2016. doi:10.1111/conl.12246.

Hayashi M, Shiratori T. Gobies of Japanese waters. Tokyo: Hankyu Communications Co., Ltd.; 2013 (in Japanese).

hk-fish.net. Introduction \& map of Hong Kong waters. 2016a. http://www.hk-fish. net/eng/database/intro/intro.htm. Accessed 12 Jan 2016.

hk-fish.net. Hong Kong marine fish database. 2016b. http://www.hk-fish.net/eng/ database/index.htm. Accessed 12 Jan 2016

Kaufman LS, Ebersole J. Microtopography and the organization of two assemblages of coral reef fishes in the West Indies. J Exp Mar Biol Ecol. 1984;78:253-68.

Lau PPF, Li LWH. Identification guide to fishes in the live seafood trade of the Asia-Pacific region. Hong Kong: WWF-Hong Kong and Agriculture, Fisheries and Conservation Department; 2000.

Lecchini D. Spatial and behavioural patterns of reef habitat settlement by fish larvae. Mar Ecol Prog Ser. 2005;301:247-52.

Leis JM, McCormick MI. The biology, behavior, and ecology of the pelagic, larval of coral reef fishes. In: Sale P, editor. Coral reef fishes: dynamics and diversity in a complex ecosystem. California: Academic; 2002. p. 171-200.

Liu J. Subphylum vertebrata Cuvier, 1812. In: Liu JY, editor. Checklist of marine biota of China seas. Beijing: China Science Publishing \& Media Ltd; 2008. p. 886-1066.

Matsuura K. Taxonomy and systematics of tetraodontiform fishes: a review focusing primarily on progress in the period from 1980 to 2014. Ichthyol Res. 2015;62:72-113.

Mooi RD. Pempheridae. Sweepers (bullseyes). In: Carpenter KE, Niem VH, editors. FAO species identification guide for fishery purposes. The living marine resources of the Western Central Pacific. Volume 5. Bony fishes part 3 (Menidae to Pomacentridae). Rome: FAO; 2001. p. 2791-3380.

Morton M, Morton J. The sea shore ecology of Hong Kong. Hong Kong: Hong Kong University Press; 1983.

Randall JE, Allen GR, Steene C. Fishes of the Great Barrier Reef and Coral Sea. Bathurst: Crawford House Publishing Pty Ltd.; 1997.

Sadovy Y, Cornish AS. Reef fishes of Hong Kong. Hong Kong: Hong Kong University Press; 2000.

Shao KT. Taiwan fish database. 2016a. http://fishdb.sinica.edu.tw/chi/species. php?id=381703. Accessed 8 Jan 2016.

Shao KT. Taiwan fish database. 2016b. http://fishdb.sinica.edu.tw/chi/species. php?id=381968. Accessed 17 Jan 2016

Shao KT. Taiwan fish database. 2016c. http://fishdb.sinica.edu.tw/chi/species. php?id=383396. Accessed 17 Jan 2016

Shoichi K. Marine fish illustrated. Tokyo: Seibundo Shinkosha; 2014 (in Japanese).

Thresher RE, Kuris AM. Options for managing invasive marine species. Biol Invas. 2004:6:295-300.

To A, Situ A. New comers to the local fish list, or unwelcome exotics! Porcupine! 2005;22:6-7.

To A, Ching K, Shea S. Hong Kong reef fish photo guide. Hong Kong: Eco-Education and Resources Centre; 2013.

Wu H. Vertebrata. In: Huang Z, Lin M, editors. The living species and their illustrations in China's seas (part I) the living species in China's seas. Beijing: China Ocean Press; 2012. p. 919-1160.

Yanagisawa Y. Genus Amblyeleotris (Gobiidae) of Japan and geographical variations of A. japonica Takagi. Publ Seto Mar Biol Lab. 1976:23:145-68. 